\title{
SYN'THESIS AND ANALYSIS OF NOVEL POLYMERS WITH HIGH PERMSELECTIVITY AND PERMEABILITY IN GAS SEPARATION APPLICATIONS
}

\author{
Progress Report
}

December 1990 - November 1991

Submitted by

W. J. Koros and D. R Paul Department of Chemical Engineering The University of Texas at Austin Austin, Texas 78712-1062

(512) $471-5866$

(512) $471-5392$

November 15, 1991

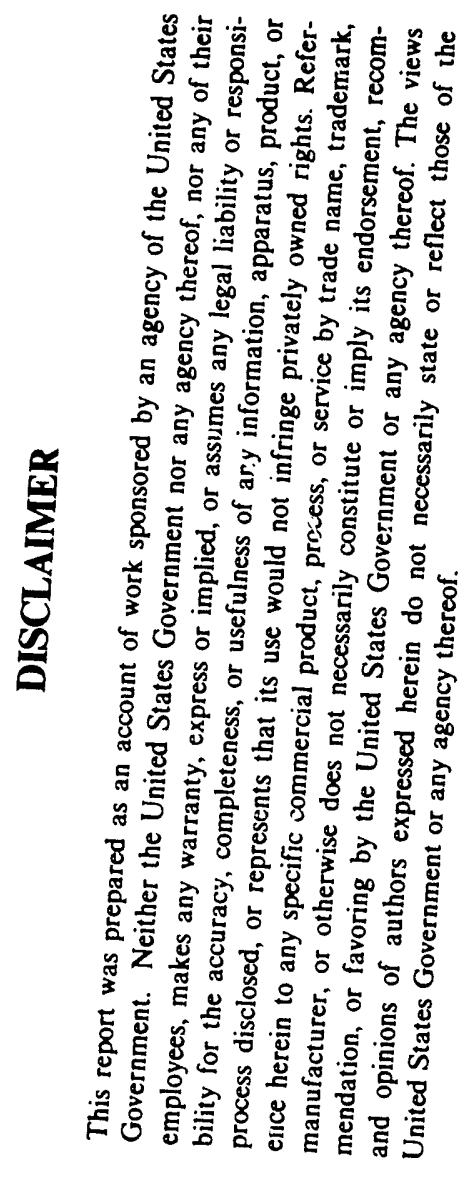

PREPARED FOR THE U.S. DEPARTMENT OF ENERGY UNDER CONTRACT NUMBER: DE-FG05-86ER13507

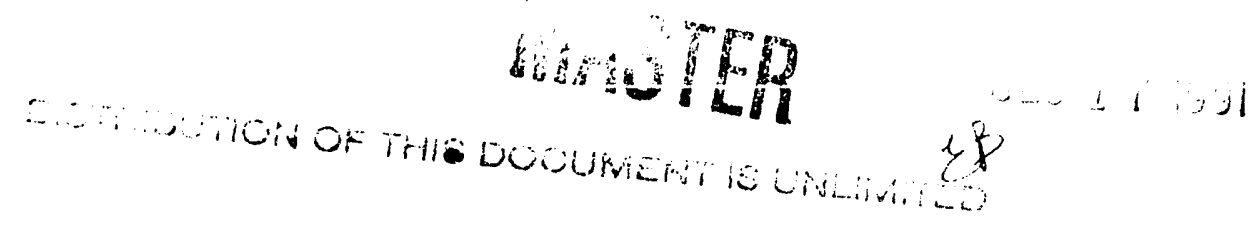




\section{Summary of Activities}

During the past eleven months of project support we have made significant progress toward our program goal to develop advanced materials for gas separation membrane applications. The following specific achievements are noteworthy.

- Synthesized and completed characterization of permeability and selectivity properties of a group of polysulfones and polyether ketones with the potential for higher use temperatures.

- Synthesized and characterized the members of a series of polyesters derived from spirobiindane bisphenol monomer in conjunction with meta and para substituted diacid chlorides. Work was reported in our last annual report on a polycarbonate derived from the spirobiindane monomer.

- Synthesized and characterized the gas transport and thermal properties of diphenyl substituted polyphenylene oxide. The diphenyl substituted material has a potential for higher temperature applications than the standard dimethyl substituted polymer. Also the temperature dependence of the gas transport properties for the oxygen/nitrogen system was characterized over the range from 35 to $65^{\circ} \mathrm{C}$ for both of these analog materials.

- Five new papers have appeared in print during the year, and we have prepared five new manuscripts and given four presentations at technical meetings under support of DE-FG05-86ER13507. This brings the total to sixteen publications in print produced under our five-and-a-half years of DOE support. We are currently preparing four additional publications which will be submitted by the end of the sixth year of our support. 


\section{Details of Program Activities}

The following sections provide additional information about the technical items noted above. The listing of publications, presentations and manuscripts prepared since the past progress report are given in a separate section at the end of the report.

\section{Polysulfones and Polyether Ketones}

Extension of our understanding of the detailed structure-property characteristics of the polysulfone family was continued in this fifth year of grant support. The polysulfones are very important since they have proven to have good asymmetric membrane forming capabilities. For instance, the standard bisphenol $\mathrm{A}$ based polysulfone formed by condensation with dichlorodiphenyl sulfone is the basis for the highly successful Prism $\otimes$ and Prism alpha $\otimes$ gas separation membrane systems.

Extensions of our prior work were achieved by formation of biphenylene based polysulfones shown as items $2-4$ in Table 1 . The $\mathrm{Tg}$ transitions were determined by DSC while the sub $\mathrm{Tg}$ transition temperatures were assessed by dynamic mechanical snalysis at 110 cycles per second. The d-spacings were determined by $x$-ray with Bragg's law applied to the maximum in the amorphous scattering response. Carbon dioxide and oxygen permeability as well as carbon dioxide/methane and oxygen/nitrogen selectivity values at $35^{\circ} \mathrm{C}$ are shown for these materials in Table 2. Item 1, of course, is the bisphenol A monomer used in the formation of standard polysulfone and is included for comparison purposes. Perhaps the most unusual structure considered is the hexamethylbiphenylene ether polysulfone synthesized in our labs. As shown in Table 1, this material exhibits a glass transition of $295^{\circ} \mathrm{C}$ with an attractive trade-off between permeability and permselectivity for the carbon dioxide/methane and oxygen/nitrogen systems. 
Table 1a: Standard Bisphenol A Polysulfone and Biphenylene Polysulfones

Standard PSF

Table 1b: Biphenylene Polymers

\begin{tabular}{|c|c|c|c|c|c|c|c|c|}
\hline Polymer & $\begin{array}{c}\mathrm{Tg} \\
\left({ }^{\circ} \mathrm{C}\right)\end{array}$ & $\begin{array}{c}\mathrm{T} \gamma \\
\left({ }^{\circ} \mathrm{C}\right)\end{array}$ & $\begin{array}{c}\text { density } \\
(\mathrm{g} / \mathrm{cc})\end{array}$ & $\begin{array}{c}\mathrm{d}- \\
\text { spacing } \\
(\AA)\end{array}$ & $\begin{array}{c}\mathrm{P}_{\mathrm{CO}} \\
(\text { Barrers })\end{array}$ & $\begin{array}{c}\mathrm{P}_{\mathrm{CO}_{2}} \\
\mathrm{P}_{\mathrm{CH}_{4}}\end{array}$ & $\begin{array}{c}\mathrm{P}_{2} \\
(\text { Barrers })\end{array}$ & $\frac{\mathrm{P}_{\mathrm{O}_{2}}}{\mathrm{P}_{\mathrm{N}_{4}}}$ \\
\hline $\begin{array}{c}\text { Standard } \\
\text { PSF }\end{array}$ & 185 & -85 & 1.24 & 5.0 & 05.6 & 22 & 1.4 & 5.6 \\
\hline BIPSF & 231 & -83 & 1.29 & 4.8 & 05.6 & 22 & 1.3 & 5.5 \\
\hline TMBIPSF & 288 & $\begin{array}{c}-90, \\
50\end{array}$ & 1.19 & 5.3 & 31.8 & 25 & 5.8 & 4.8 \\
\hline
\end{tabular}

$\mathrm{CO}_{2}$ and $\mathrm{CH}_{4}$ at $10 \mathrm{~atm}, \mathrm{O}_{2}$ and $\mathrm{N}_{2}$ at $1 \mathrm{~atm}$, both systems at $35^{\circ} \mathrm{C}$ 
A related, smaller scale study done to compare properties of polycarbonates, polysulfones and polyetherketones should also be noted here. The structures of these materials are shown in Table 2, and their physical properties are shown in Table 3a. Summaries of permeabilities and selectivities for the carbon dioxide/ methane system and oxygen/nitrogen system are given in Table 3b. A direct comparison of the effect of the ketone versus the sulfone group is possible from these data. The structures referred to as PBK, PBKS, and PBSF have analogous structures that only differ by sulfone or ketone groups in the repeat unit. The higher permeability coefficients for PBSF versus the analogous PBK is interesting. Consistent with typical trade off behavior found related to permeability and selectivity, the selectivity coefficients for the bisketone polymer are higher than those for the bissulfone polymer.

Table 2: Poly(Aryl Ether Bisketones) \& Poly(Aryl Ether Bissulfones)

\begin{tabular}{|c|c|}
\hline 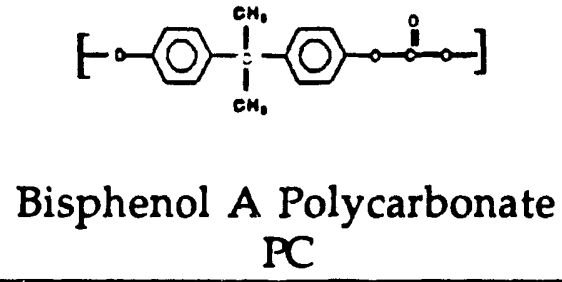 & 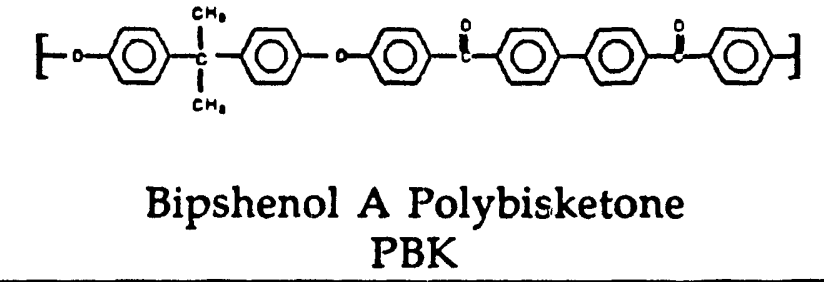 \\
\hline $\begin{array}{l}\text { Biphenol A Polysulfone } \\
\text { PSF }\end{array}$ & $\begin{array}{c}\text { Fo-(0)-(O)-O(O) } \\
\text { Bipshenol A Polybissulfone } \\
\text { PBSF }\end{array}$ \\
\hline & $\begin{array}{c}\text { [-(O) } \\
\text { Bisphenol S Polybisketone } \\
\text { PBK-S }\end{array}$ \\
\hline
\end{tabular}


Table 3a: Summary of Bis Ketone and Bis Sulfone Polymer Properties

\begin{tabular}{|c|c|c|c|c|c|}
\hline Polymer & $\begin{array}{c}\mathrm{Tg} \\
\left({ }^{\circ} \mathrm{C}\right)\end{array}$ & $\begin{array}{c}\mathrm{d} \text {-spacing } \\
(\AA)\end{array}$ & $\begin{array}{c}\text { Density } \\
(\mathrm{g} / \mathrm{cc})\end{array}$ & $\begin{array}{c}\mathrm{FFV} \\
\left(\frac{\mathrm{V}-\mathrm{V}_{\mathrm{O}}}{\mathrm{V}}\right)\end{array}$ & $\begin{array}{c}\mathrm{T} \gamma \\
\left({ }^{\circ} \mathrm{C}\right)\end{array}$ \\
\hline PC & 150 & 5.2 & 1.20 & 0.164 & -80 \\
\hline PBK & 180 & 4.9 & 1.12 & 0.146 & -70 \\
\hline PBK-S & 219 & 4.9 & 1.29 & 0.143 & -50 \\
\hline PSF & 185 & 5.0 & 1.24 & 0.156 & -85 \\
\hline PBSF & 240 & 5.0 & 1.27 & 0.155 & -80 \\
\hline
\end{tabular}

Table 3b: Permeabilities \& Selectivites for Bisketone \& Bissulfone Polymers

\begin{tabular}{|c|c|c|c|c|}
\hline Polymer & $\begin{array}{c}\mathrm{PCO}_{2} \\
\text { (Barrers) }\end{array}$ & $\frac{\mathrm{P}_{\mathrm{CO}_{2}}}{\mathrm{P}_{\mathrm{CH}_{4}}}$ & $\begin{array}{c}\mathrm{PO}_{2} \\
\text { (Barrers) }\end{array}$ & $\frac{\mathrm{P}_{\mathrm{O}_{2}}}{\mathrm{P}_{\mathrm{N}_{2}}}$ \\
\hline 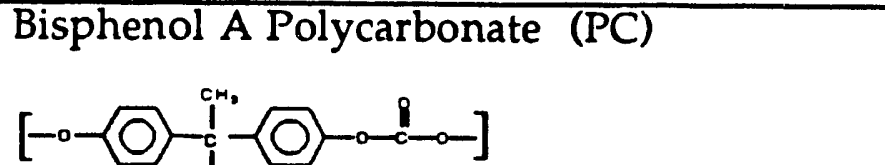 & 6.8 & 23 & 1.61 & 5.1 \\
\hline $\begin{array}{l}\text { Bisphenol A Polybisketone (PBK) } \\
{[-\circ \text { (O) (O)-(O)-(O) (O) - (O) }}\end{array}$ & 3.3 & 23 & 0.75 & 5.8 \\
\hline Bisphenol S Polybisketone (PBK-S) & 3.27 & 28 & 0.64 & 6.0 \\
\hline 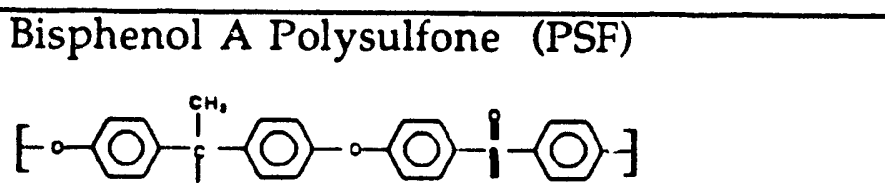 & 5.6 & 22 & 1.39 & 5.6 \\
\hline $\begin{array}{l}\text { Bisphenol A Polybissulfone (PBSF) } \\
\text { Fa-(O)-(O)- (O)-(O)-(O)- }\end{array}$ & 7.35 & 17 & 2.39 & 5.1 \\
\hline
\end{tabular}

$\mathrm{CO}_{2} \& \mathrm{CH}_{4}$ data at $10 \mathrm{~atm}, \mathrm{O}_{2} \& \mathrm{~N}_{2}$ data at $2 \mathrm{~atm}$ 


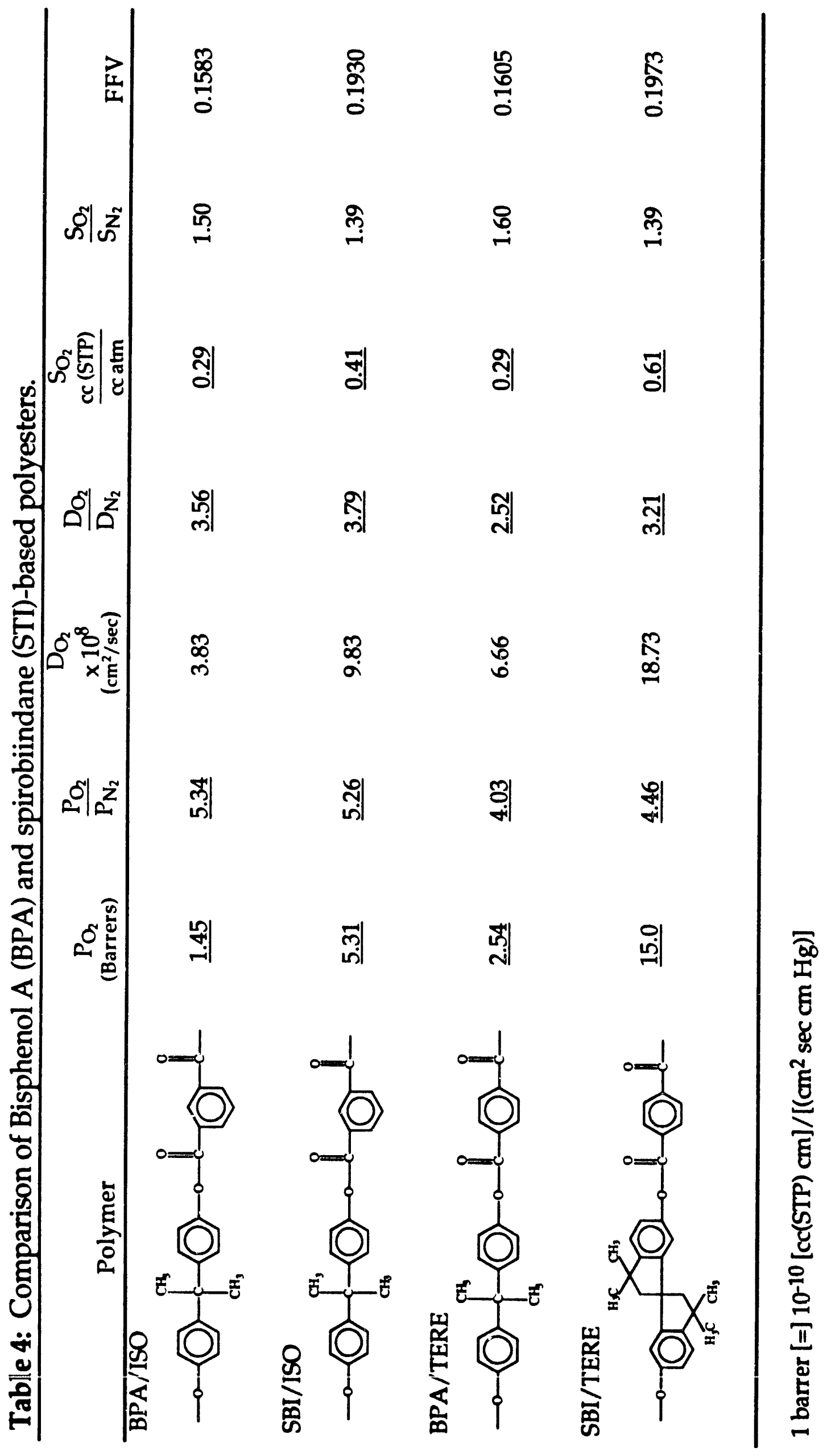




\section{Aromatic Polyesters Derived from Spirobiindane}

In our last annual report we provided data for the permeability and selectivity properties of polycarbonate derived from spirobiindane diol structure. This polymer had been provided to us by request from the General Electric Company because our assessment of its combination of structurally inhibited packing and motion suggested that it would be a good candidate membrane material for oxygen/nitrogen separation. As was reported last year, this turned out to be a correct assessment, and the polycarbonate had attractive properties.

Also reported last year was synthesis and permeability and selectivity characterization of the individual polyesters derived from terephthalic and isophthalic acids condensed with bisphenol $\mathrm{A}$ monomer. These materials were chosen as benchmarks for comparison in a series of polyesters planned for synthesis by our group. As a logical extension of the polycarbonate work, the spirobiindane diol was used in the formation of polyesters based on the isophthalic and terephthalic acid chlorides. Over the past year we have completed the characterizations of these polyesters and compared their properties to the aromatic polyesters derived from the more flexible and less packing inhibited bisphenol $\mathrm{A}$ monomer. These results are being summarized in a paper currently being prepared for publication, and the essential elements of that paper are abstracted here.

As shown in Table 4, a comparison of the isophthalic and terephthalic acid polyesters derived from bisphenol $A$ and spirobiindane reveal attractive tradeoffs in productivity and selectivity as a result of the replacement of the flexible bisphenol $\mathrm{A}$ with the spirobiindane monomer. The higher permeabilities can be attributed to both higher diffusion coefficients and solubilities of oxygen in the spiro-based materials. On the other hand, the overall selectivity of the two materials are rather similar, and this derives from a higher mobility selectivity for the spiro-based materials and a lower solubility selectivity in these more open structures. The 
detailed reason for this lower solubility selectivity of oxygen over nitrogen is not well understood but has been observed in other cases where the matrix is "opened" by the addition of structural or packing disrupting units such as the spirobiindane unit.

\section{Phenol Substituted Polymers}

The objective of this section of our work is to explore materials useful in oxidizing environments and in higher temperature applications while understanding the fundamental effects on the gas transport properties of polymers caused by attachment of different pendant groups on the backbone. Aromatic groups are of particular interest due to their ability to provide higher temperature stability to membrane materials. The first two materials being compared in this respect are 2,6-dimethyl polyphenylene oxide and a new material, PDPO, polydiphenyldiphenylene oxide. The structures of these two materials are shown below:

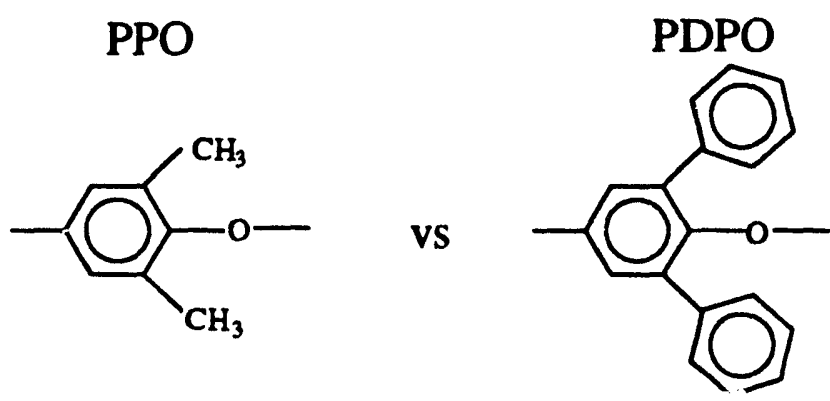

Table 5 compares thermal transitions, densities, d-spacings, and free volume fractions for the two materials. The $T_{\beta}$ and $T_{\gamma}$ temperatures are sub $\mathrm{Tg}$ transitinns characteristic of the motions of the backbone or pendant groups in the polymer. The glass transition of the diphenyl substituted material is raised to aimost $230^{\circ} \mathrm{C}$. It was rather surprising that the temperature was not raised more, given the tremendous increase in bulk associated with the substitution. 
Table 5: Comparison of Phenylene Oxides Properties.

\begin{tabular}{|c|c|c|c|c|c|c|}
\hline & $\mathrm{T}_{\mathrm{g}}(\mathrm{a})\left({ }^{\circ} \mathrm{C}\right)$ & $\mathrm{T}_{\beta}(\mathrm{b})\left({ }^{\circ} \mathrm{C}\right)$ & $\mathrm{T}_{\gamma}(\mathrm{b})\left({ }^{\circ} \mathrm{C}\right)$ & $d^{(c)}(\AA)$ & $\mathrm{T}_{\mathrm{d}}(\mathrm{d})\left({ }^{\circ} \mathrm{C}\right)$ & $\left(V-V_{0}\right) / V$ \\
\hline PPO & 212 & -55 & - & 6.1 & 450 & 0.1988 \\
\hline PDPO & 229 & 80 & -140 & 5.0 & 564 & 0.1882 \\
\hline
\end{tabular}
a) at $20^{\circ} \mathrm{C} / \mathrm{min}$
b) From A. Eisenberg and H. Cayrol, J. Polym. Sci. Part C, 35, 129 (1971)
c) From $x$-ray diffraction data $\lambda=1.54 \AA$
d) From TGA at $10 \mathrm{C} / \mathrm{min}$

Complete characterization in terms of permeability, solubility, and diffusivity for these two materials are reported in Tables $6 \mathrm{a}-\mathrm{c}$ for methane/nitrogen and carbon dioxide at $35^{\circ} \mathrm{C}$. The selectivities of helium relative to methane, oxygen relative to nitrogen, and carbon dioxide relative to methane for the highly hindered diphenylphenylene oxide are rather low. As is shown in the table of thermal properties, $T_{\beta}$ which is the next thermal transition peak below the glass transition temperature, appears to have been raised dramatically from $-55^{\circ} \mathrm{C}$ to $+80^{\circ} \mathrm{C}$ by the diphenyl substitution. This might, at first glance, suggest a significant inhibition of sub-Tg motion; however, a very low transition peak not apparent in 2,6 dimethylphenylene oxide is apparent at $-140^{\circ} \mathrm{C}$ in the diphenylphenylene oxide. Such low temperature motions are generally thought to be associated with very small scale movement with possible importance to diffusion in the glass. The motion associated with $T_{\beta}$, on the other hand, may be more significant for mechanical properties. If this is correct, more sub $\mathrm{Tg}$ motion may actually be present in the diphenylphenylene oxide than exists in the 2,6 dimethylphenylene oxide.

Table 6a: Comparison of Gas Permeability Coefficients of PPO and PDPO

\begin{tabular}{|c|c|c|c|c|c|}
\hline & $\mathrm{He}$ & $\mathrm{N}_{2}$ & $\mathrm{CH}_{4}$ & $\mathrm{O}_{2}$ & $\mathrm{CO}_{2}$ \\
\hline PPO & 8.2 & 3.5 & 4.1 & 14.6 & 6.5 \\
\hline PDPO & 3.3 & 1.6 & 2.7 & 7.7 & 4.0 \\
\hline
\end{tabular}

Barrer $=10^{-10}\left[\mathrm{~cm}^{3}\left(\right.\right.$ STP) $\left.-\mathrm{cm} / \mathrm{cm}^{2}-\mathrm{s}-\mathrm{cm} \mathrm{Hg}\right]$ 
Table 6b: Apparent Solubility Coefficients, $\mathrm{S}_{\mathrm{a}}\left[\mathrm{cc}(\mathrm{STP}) /\left(\mathrm{cm}^{3} \mathrm{~atm}\right)\right]$, @ 20 atm for PPO and PDPO.

\begin{tabular}{|c|c|c|c|}
\hline & $\mathrm{CH}_{4}$ & $\mathrm{~N}_{2}$ & $\mathrm{CO}_{2}$ \\
\hline PPO & 0.7 & 0.28 & 2.1 \\
\hline PDPO & 0.7 & 0.21 & 1.8 \\
\hline
\end{tabular}

Table 6c: Apparent Diffusion Coefficients, $D_{a}$, @ 20 atm for PPO and PDPO.

\begin{tabular}{|c|c|c|c|}
\hline \multicolumn{4}{c|}{$\mathrm{D}_{\mathrm{a}} \times 10^{8}\left(\mathrm{~cm}^{2} / \mathrm{s}\right)$} \\
\hline PPO & $\mathrm{CH}_{4}$ & $\mathrm{~N}_{2}$ & $\mathrm{CO}_{2}$ \\
\hline PDPO & 2.9 & 8.0 & 18.3 \\
\hline
\end{tabular}

Additional work to characterize temperature dependence of the permeability and diffusion coefficients in a wider variety of materials of systematically varied structure is underway in these two materials as weli as in our group and should be available by the close of the sixth year of grant support.

In addition to the substituted polyphenylene oxide materials, a large number of phenyl substituted polysulfones and polycartonates are planned for preparation in the final year of grant support. Structures and their methyl substituted analogs are shown in Tables $7 \mathrm{a}$ and $7 \mathrm{~b}$. We will begin characterization both in terms of thermal properties and gas scrption and transport properties as soon as the synthesis of these materials is completed. This work should also be underway partially completed by the end of the sixth year of grant support and will continue under a renewal proposal. 
Table 7a: Polycarbonates \& Polysulfones Based on Bisphenol-A structure with Methyl and Phenyl Substitutions Proposed for Study.

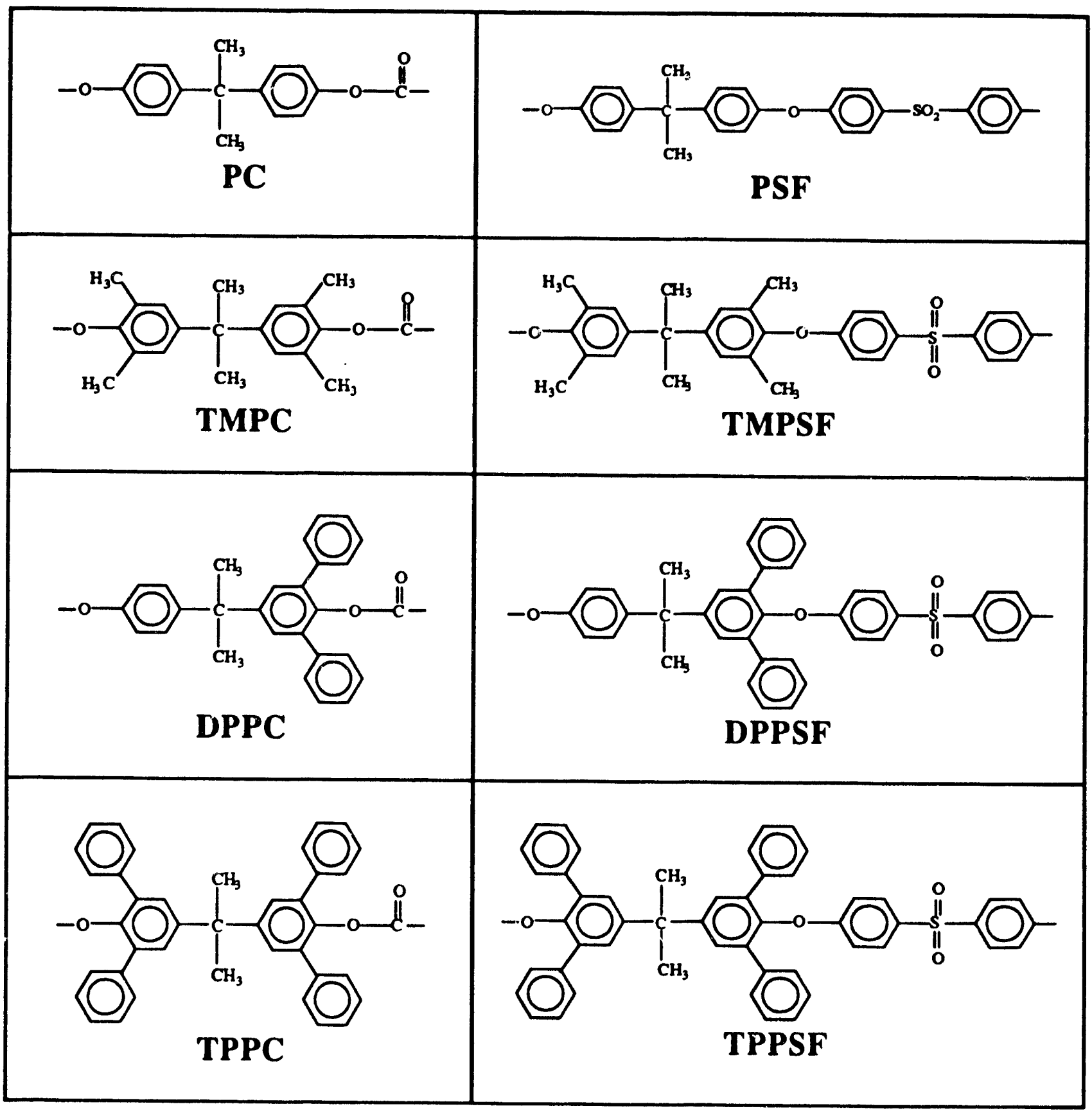


Table 7b: Polycarbonates \& Polysulfones Based on Bisphenol. Variation of Structure with Methyl and Phenyl Substitutions.

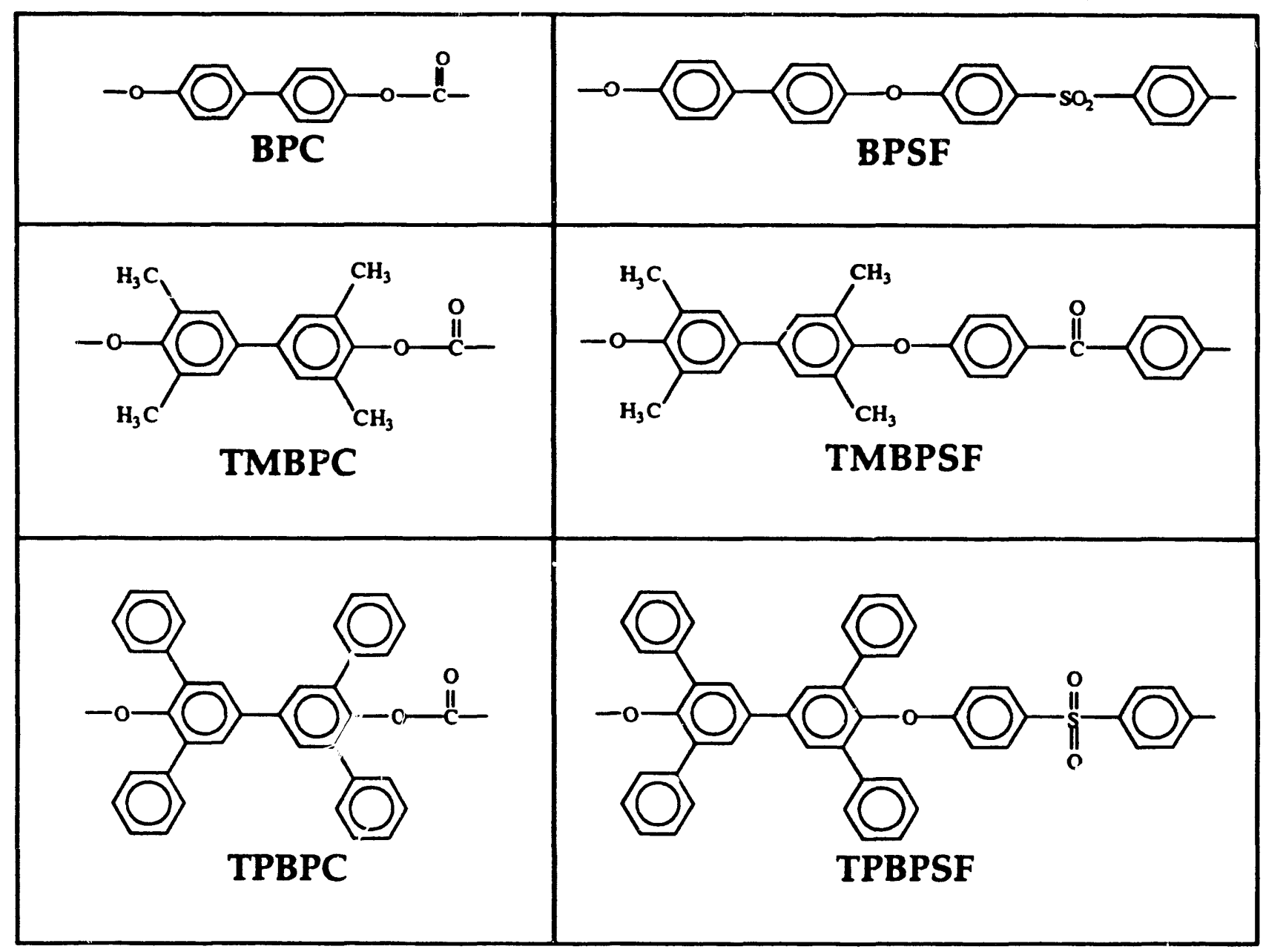




\section{PUBLICATIONS AND PRESENTATIONS OVER THE PAST YEAR GIVEN UNDER DOE SPONSORSHIP GIVEN SINCE LAST PROGRESS REPORT}

\section{Articles Published}

1. McHattie, J. S., W. J. Koros and D. R. Paul, Effect of Isopropylidene Replacement on Gas Transport Properties of Polycarbonates", J. Polym. Sci.; Polym. Phys. Ed., 29, 731 (1991).

2. McHattie, J. S., W. J. Koros and D. R. Paul, "Gas Transport Properties of Polysulfones. Part I: Role of Symmetry of Methyl Group Placement on Bisphenol-A Rings", Polymer, 32, 840 (1991).

3. McHattie, J. S., W. J. Koros and D. R. Paul, "Gas Transport of Polysulfones. Part II: Effect of Bisphenol Connector Groups", Polymer, 32, 840 (1991).

4. Koros, W. J. and D. R. B. Walker, "Gas Separation Membrane Materials Selection Criteria: Weakly and Strongly Interacting Feed Component Situations", Polymer Journal, 23 (1991).

5. Mohr, J. M., D. R. Paul, G. L. Tullos and P. E. Cassidy, "Gas Transport Properties of a Series of Poly(ether ketone) Polymers", Polymer, 32, 2387 (1991).

\section{Publications Accepted and in Press}

6. Koros, W. J., M. W. Hellums and D. R. Paul, "Gas Transport in HalogenContaining Aromatic Polycarbonates", J. Appl. Polym. Sci.

7. Hellums, M. W., W. J. Koros and J. C. Schmidhauser, "Gas Transport in Spirobiindane Polycarbonate", J. Membr. Sci.

8. Story, B. J. and W. J. Koros, "Sorption and Transport of $\mathrm{CO} 2$ and $\mathrm{CH} 4$ in Chemically Modified Poly(phenylene oxide)", J. Membr. Sci.

9. Koros, W. J., M. R. Coleman, and D. R. Walker, "Controlled Permeability Polymer Membranes", Annual Review of Materials Science.

10. Aitken, C. L., J. S. McHattie, and D. R. Paul, "Dynamic Mechanical Behavior of Polysulfones", Macromolecules.

\section{Presentations at Technical Meetings}

1. Koros, W. J., S. C. Pesek and I. Pinnau, "Material Selection for Gas Separation", Progress in Membrane Science and Technology, Enschede, The Netherlands, 25-28 June 1991. 
2. Aitken, C., D. R. Paul and W. J. Koros, "The Gas Transport Properties of New Polysulfone Materials and their Isomers", Progress in Membrane Science and Technology, Enschede, The Netherlands, 25-28 June 1991.

3. Koros, W. J., "Material Selection for Gas Permeable Contact Lenses," Third Annual Meeting on Contact Lenses, St. Louis, Missouri, 15 March 1991.

4. Koros, W. J., "Polymers for Membrane-Based Gas Separation", Gas Separation International, Austin, Texas, 22 April 1991. 

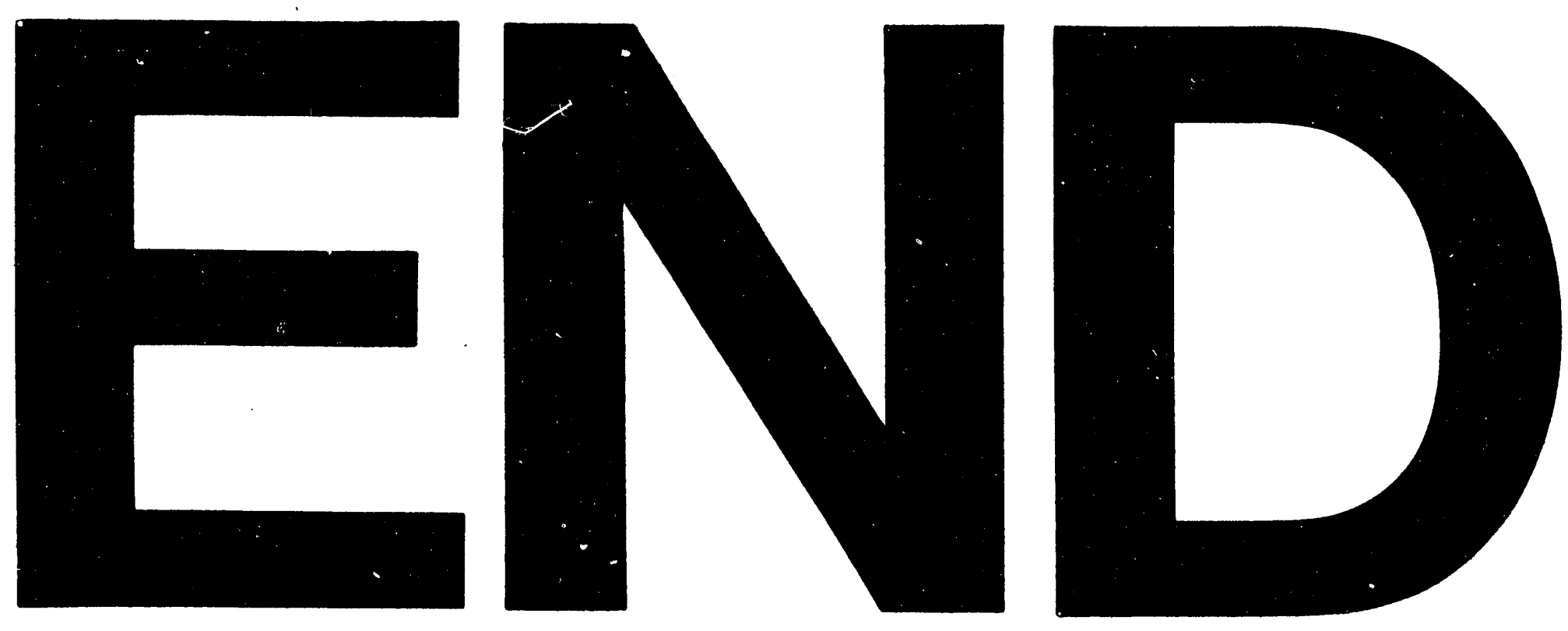

I
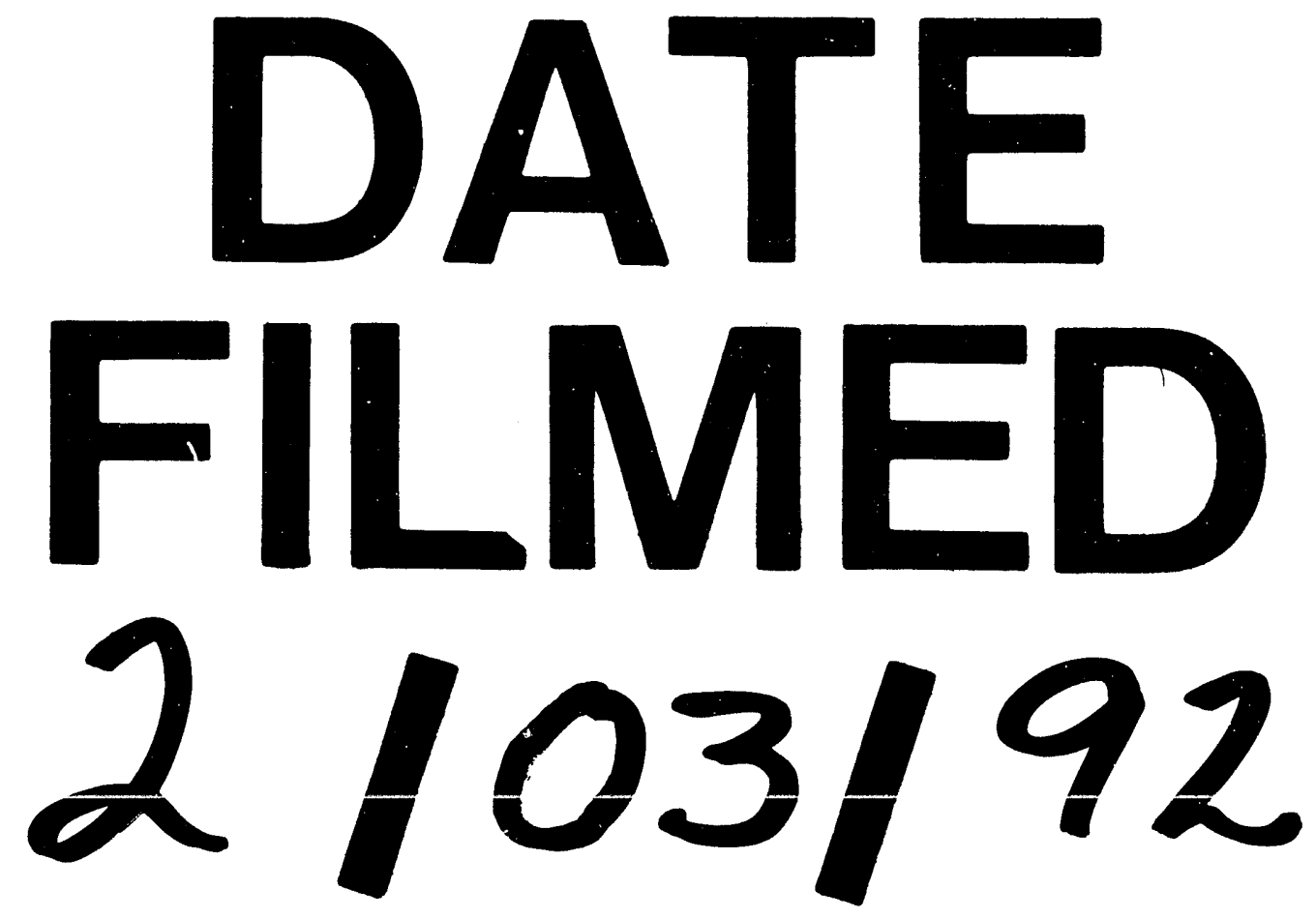
$=$ 